\title{
The Optimization Parameters of Activated Biochar Derived From Pine Pyrolysis: Application in Methylene Blue Adsorption
}

Shasha Liu

Nanjing Forestry University

Chen Shen

Nanjing Forestry University

Yuhui Wang

Nanjing Forestry University

Yong Huang

Nanjing Forestry University

Xun $\mathrm{Hu}$

Jinan University

Bin Li

Jiangsu University

Karnowo Karnowo

Universitas Negeri Semarang

Jianbin Zhou

Nanjing Forestry University

Shu Zhang ( $\nabla$ s.zhang@njfu.edu.cn )

Nanjing Forestry University

Hong Zhang

Nanjing Forestry University

\section{Research Article}

Keywords: Activated biochar, Activation, Methylene blue, Characterization analysis, Adsorption, Dynamics

Posted Date: June 7th, 2021

DOl: https://doi.org/10.21203/rs.3.rs-511912/v1

License: (c) (i) This work is licensed under a Creative Commons Attribution 4.0 International License.

Read Full License 


\section{The optimization parameters of activated biochar derived from} pine pyrolysis: Application in methylene blue adsorption

Shasha Liu ${ }^{1}$, Chen Shen ${ }^{1}$, Yuhui Wang ${ }^{1}$, Yong Huang ${ }^{1}$, Xun $\mathrm{Hu}^{2}, \mathrm{Bin}^{2} i^{3}$, Karnowo ${ }^{4}$, Jianbin Zhou ${ }^{1, *}$, Shu Zhang ${ }^{1, *}$, Hong Zhang ${ }^{1}$

${ }^{1}$ Joint International Research Laboratory of Biomass Energy and Materials, CoInnovation Center of Efficient Processing and Utilization of Forest Resources, College of Materials Science and Engineering, Nanjing Forestry University, Nanjing 210037,

China

${ }^{2}$ School of Material Science and Engineering, University of Jinan, Jinan 250022, Shandong, China

${ }^{3}$ School of Energy and Power Engineering, Jiangsu University, Zhenjiang 212013, China

${ }^{4}$ Faculty of Engineering, Universitas Negeri Semarang (UNNES), Jawa Tengah 50229, Indonesia

*Corresponding author :

E-mail:zhoujianbin@njfu.edu.cn;s.zhang@njfu.edu.cn

Abstract: To understand the interaction mechanism between adsorbent and adsorbate, activated biochar, prepared from pine sawdust using $\mathrm{CO}_{2}$ and $\mathrm{H}_{2} \mathrm{O}$ as activator, was employed to adsorb methylene blue in printing and dyeing pollutants. The pore structure, carbon structure of the aromatic ring system, and functional groups were investigated though SEM, nitrogen adsorption/desorption device (BET), Raman, and 
XPS characterization, and the adsorption kinetics and possible adsorption mechanism were also studied. The results showed that the activated biochar prepared by $\mathrm{CO}_{2}$ activation had more specific surface area, pore structure, and surface oxygen-containing functional groups than that prepared by $\mathrm{H}_{2} \mathrm{O}$, which was more conductive to improving its adsorption capacity. The electrostatic interaction between the surface oxygencontaining functional groups in the adsorbents and the $\pi-\pi$ interaction formed in the aromatic rings enhanced the adsorption capacity of activated biochar to methylene blue. The adsorption process of methylene blue by activated biochar was spontaneous, and it conformed to the pseudo-second-order kinetic characteristics and Langmuir adsorption isotherm equation. It was a monolayer adsorption and the maximum adsorption capacity was about $160 \mathrm{mg} / \mathrm{g}$. Activated biochar as an adsorbent for wastewater treatment has promising application and development prospects.

Keywords: Activated biochar; Activation; Methylene blue; Characterization analysis; Adsorption; Dynamics

\section{Introduction}

Methylene blue (MB) is widely applied to the fields of chemical reagents, biological dyes and drugs, etc. (Huang et al., 2018; Lyu et al., 2018; Yang et al., 2021). However, a large amount of organic dye wastewater generated in the printing and dyeing process brings huge environmental risks (Deng et al., 2020; Fan et al., 2017). Therefore, the realization of high-efficiency purification treatment of printing and dyeing wastewater has been the study focus of researchers. Purification treatment technologies for wastewater mainly include: physical adsorption, chemical degradation, 
and advanced oxidation technology, etc. (Kang et al., 2016; Pirsaheb et al., 2016; Wan et al., 2017). Among them, the physical adsorption represented by carbon materials has the advantages of simple process, easy operation and recovery, various adsorbents, and no secondary pollution, etc., making it the most promising technical means for industrial application in the filed of water purification (Li et al., 2019a; Xu et al., 2020; Zeng et al., 2018). Activated biochar (AC) is characterized by abundant pore structure, strong adsorption capacity, and renewability (Gao et al., 2013; Genuino et al., 2018), which is of great significant for the treatment of industrial waste liquid and the remediation of environmental pollution (Li et al., 2019b).

Choudhary et al. (Choudhary et al., 2020) used biochar activated by $\mathrm{NaOH}$ to adsorb pollutants in water. It was found that AC showed excellent adsorption capacity for organic pollutants and inorganic heavy metals. Removal of two drugs in aqueous solution by a carbonate-AC was reported by Shirani et al. (Shirani et al., 2020). The results showed that the electrostatic adsorption, hydrophobic interaction, and $\pi-\pi$ bond played crucial roles in the adsorption of AC to adsorbents. Although the biochar prepared by the chemical activation could effectively solve the removal of pollutants, the introduction of additional chemical reagents was not so environmentally friendly. It is worth mentioning that the AC prepared by physical modification, such as steam, carbon dioxide and air activation, has attracted much attention of researchers (Rajapaksha et al., 2016). Rajapaksha et al. (Rajapaksha et al., 2015) compared the effects of biochar on the adsorption of sulfamethazine in water, indicating that there was a great chemisorption process and electrostatic interaction between the $\mathrm{AC}$ and 
remover, and the steam-activated char had more advantages in adsorption capacity. Based on the research of Franciski et al. (Franciski et al., 2018), the AC prepared by $\mathrm{CO}_{2}$ activation from the bagasse pyrolysis acted as a good adsorbent in the removal of methylene blue.

However, most of studies focus on the effect of $\mathrm{AC}$ on the removal of pollutions, while the interaction between adsorbent (AC) and adsorbate, as well as the adsorption site of $\mathrm{AC}$ in the adsorption process is still unclear. Therefore, this study aims to investigate the structural characteristics of the surface on the AC prepared by physical modification (steam and carbon dioxide); and then the isothermal adsorption and kinetic analysis are carried out to further evaluate the adsorption behavior and ability of activated biochar to methylene blue. It is expected to understand the interaction mechanism between activated biochar and methylene blue.

\section{Materials and Methods}

\subsection{Preparation of activated biochar}

Biochar was obtained from the pyrolysis of pine sawdust, which was then activated by $\mathrm{CO}_{2}$ and $\mathrm{H}_{2} \mathrm{O}$ at $800{ }^{\circ} \mathrm{C}$, respectively. When $\mathrm{CO}_{2}$ was used as the active agent, the activation time was set at $1 \mathrm{~h}$ or $2 \mathrm{~h}$, and the gas flow was $200 \mathrm{~mL} / \mathrm{min}$. The prepared activated biochar (AC) was named as $\operatorname{Char}_{-X h}(X$, activation time; 1 or 2). In the case of steam activation, distilled water was injected through the syringe pump at a rate of 4 $\mathrm{mL} / \mathrm{min}$, and $2 \mathrm{~mL}$ or $4 \mathrm{~mL}$ of distilled water was injected into $1 \mathrm{~g}$ char. The generated AC was labeled as $\operatorname{Char}_{-Y m L}(Y$, distilled water amount; 2 or 4).

\subsection{Characterization of AC}


The changes of surface morphology were observed by scanning electron microscopy (SEM, Quanta 200) with magnification of 2000 times. In order to obtain the pore structure parameters, AC was characterized by an isothermal nitrogen adsorption-desorption device (Specific Surface Area Analyzer, Autosorb-iQ). The chemical forms of carbon and oxygen species in the AC were detected by X-ray photoelectron spectroscopy (XPS, AXIS UltraDLD), and a C1s peak $(284.8 \mathrm{eV})$ was employed to test the energy correction. The change of carbon skeleton was analyzed through Raman spectrometer (Themor DXR532).

2.3 The experiment of adsorption performance

\subsubsection{Isothermal adsorption}

$5 \mathrm{mg}$ of each AC sample was selected into $50 \mathrm{~mL}$ of MB solution with different initial concentrations $(7.5,10,12.5,15,17.5$, and $20 \mathrm{mg} / \mathrm{L})$. AC samples were extracted after the constant temperature and vibration for $12 \mathrm{~h}$ at a rotating speed of $300 \mathrm{r} / \mathrm{min}$ and $298 \mathrm{~K}$, and then the absorption wavelength of MB was measured at $664 \mathrm{~nm}$ with an ultraviolet spectrophotometer after filtration by a filter membrane. The equilibrium adsorption amount $\mathrm{q}_{\mathrm{e}}(\mathrm{mg} / \mathrm{g})$ of $\mathrm{MB}$ in the $\mathrm{AC}$ adsorption solution was obtained by Eq. (1).

$$
q_{e}=\frac{\left(c_{o}-c_{e}\right) V}{m}
$$

where $c_{o}$ and $c_{e}(\mathrm{mg} / \mathrm{L})$ are the initial and equilibrium concentrations of $\mathrm{MB} ; \mathrm{V}$ is the volume of MB solution ( $\mathrm{mL})$; $\mathrm{m}$ is the mass of $\mathrm{AC}$.

In order to study the influence of adsorption equilibrium, the most commonly used Langmuir isotherm model was selected to evaluate the adsorption behavior of MB and 
AC (Eq. (2)).

$$
\frac{c_{e}}{q_{e}}=\frac{c_{e}}{q_{L}}+\frac{1}{q_{L} K_{L}}
$$

where $\mathrm{q}_{\mathrm{e}}(\mathrm{mg} / \mathrm{g})$ is the adsorption amount of $\mathrm{MB}$ at adsorption equilibrium; $\mathrm{q}_{\mathrm{L}}(\mathrm{mg} / \mathrm{g})$ is the adsorption amount of $\mathrm{MB}$ at adsorption saturation; $\mathrm{K}_{\mathrm{L}}(\mathrm{L} / \mathrm{mg})$ is the constant obtained by Langmuir model fitting.

\subsubsection{Adsorption kinetics}

$5 \mathrm{mg}$ of each AC sample was added into $50 \mathrm{~mL}$ of MB solution with an initial concentration of $20 \mathrm{mg} / \mathrm{L}$, and the adsorption experiment was carried out by the rotation speed was $300 \mathrm{r} / \mathrm{min}$ at room temperature. The solution samples were taken at 2-12 $\mathrm{h}$, and each sampling interval was $2 \mathrm{~h}$. After being filtered by the filter membrane, the instantaneous adsorption $\mathrm{q}_{\mathrm{t}}(\mathrm{mg} / \mathrm{g})$ of $\mathrm{MB}$ was calculated by Eq. (3).

$$
q_{t}=\frac{\left(c_{o}-c_{t}\right) V}{m}
$$

where $c_{t}(\mathrm{mg} / \mathrm{L})$ is the concentration of $\mathrm{MB}$ at time $\mathrm{t}$; $\mathrm{V}$ is the volume of MB solution $(\mathrm{mL}) ; \mathrm{m}$ is the mass of AC.

To understand the kinetic adsorption mechanism and process of MB-AC system, and predict the relationship between adsorption rate and time, the pseudo-first-order model (Eq. (4)) and pseudo-second-order model (Eq. (5)) were used for data analysis.

$$
\begin{aligned}
\ln \left(q_{e}-q_{t}\right) & =\ln q_{e}-K_{1} \mathrm{t} \\
\frac{t}{q_{t}} & =\frac{1}{q_{e}^{2} K_{2}}+\frac{t}{q_{e}}
\end{aligned}
$$

where $\mathrm{q}_{\mathrm{e}}$ and $\mathrm{q}_{\mathrm{t}}$ represent the adsorption amount $(\mathrm{mg} / \mathrm{g})$ of $\mathrm{MB}$ at the time of equilibrium and $t$ respectively; $\mathrm{K}_{1}$ is the pseudo-first-order rate constant $\left(\mathrm{min}^{-1}\right) ; \mathrm{K}_{2}$ is the pseudo-second-order rate constant $(\mathrm{g} /(\mathrm{mg} \cdot \mathrm{min}))$; $\mathrm{t}$ is the adsorption time $(\mathrm{min})$. 


\section{Results and discussion}

Table 1. The pore structure parameters of AC

\begin{tabular}{cccc}
\hline Sample & Specific surface area $\left(\mathrm{m}^{2} / \mathrm{g}\right)$ & Pore volume $\left(\mathrm{cm}^{3} / \mathrm{g}\right)$ & Pore size $(\mathrm{nm})$ \\
\hline Char $-1 \mathrm{~h}$ & 779.07 & 0.41 & 2.68 \\
Char- $_{-2 \mathrm{~h}}$ & 906.44 & 0.46 & 2.67 \\
Char-2mL & 582.23 & 0.37 & 2.54 \\
Char-4mL & 689.13 & 0.59 & 3.45 \\
\hline
\end{tabular}

\subsection{Characterization analysis of AC}

\subsubsection{The analysis of morphology and porosity}

The adsorption properties of carbon materials are closely related to the pore size.

Therefore, it is of great significance to analyze the pore distribution for the adsorption of MB. Figure 1 showed the isotherm of nitrogen adsorption and desorption for AC, and the specific pore structure parameters were listed in Table 1.
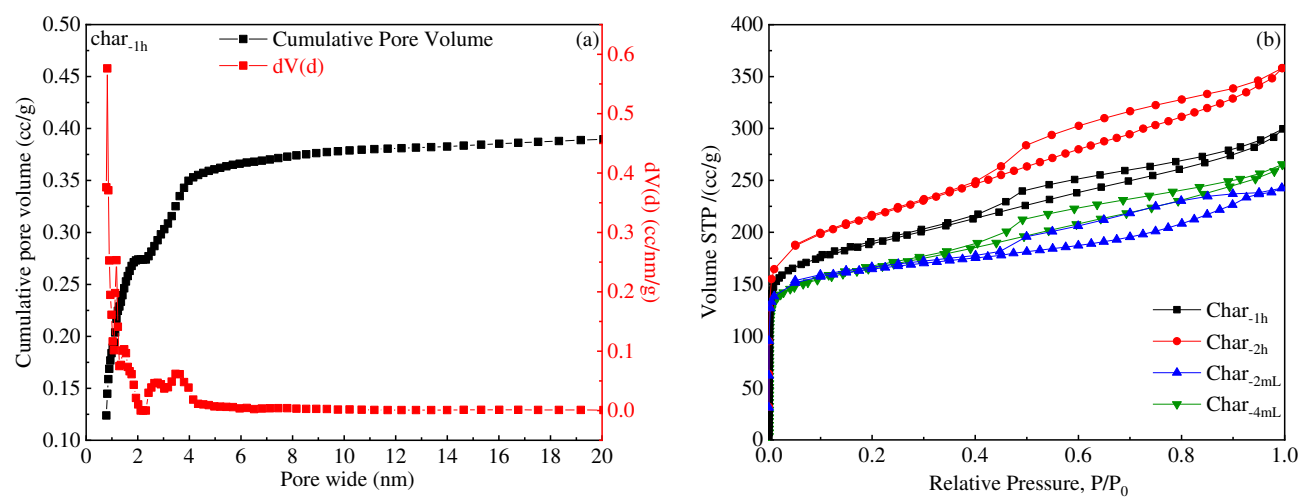

Figure 1. (a) Diagram of pore distribution; (b) $\mathrm{N}_{2}$ adsorption/desorption isotherms of AC.
143 
which led to the phenomenon of capillary condensation in mesoporous adsorption under high pressure (Tran et al., 2017). Table 1 showed that the pore structure of AC activated by carbon dioxide was more developed than that of $\mathrm{AC}$ activated by water vapor, with larger specific surface area. In addition, the pore volume and pore size of AC prepared by $\mathrm{CO}_{2}$ had smaller changes, while the changes of $\mathrm{AC}$ activated by $\mathrm{H}_{2} \mathrm{O}$ were obvious. According to the report by Feng et al. (Feng et al., 2017a; Feng et al., 2017b), $\mathrm{CO}_{2}$ activation mainly changed the surface structure of biochar, resulting in a small size structure; while $\mathrm{H}_{2} \mathrm{O}$ was able to infiltrate into the carbon matrix of coke particles, leading to large pore size structure regenerated from inside to outside on AC surface. Therefore, compared with $\mathrm{H}_{2} \mathrm{O}$ activation, the $\mathrm{AC}$ prepared by $\mathrm{CO}_{2}$ activation had a uniform pore distribution and a higher specific surface area, which provided favorable conditions for better adsorption of MB.
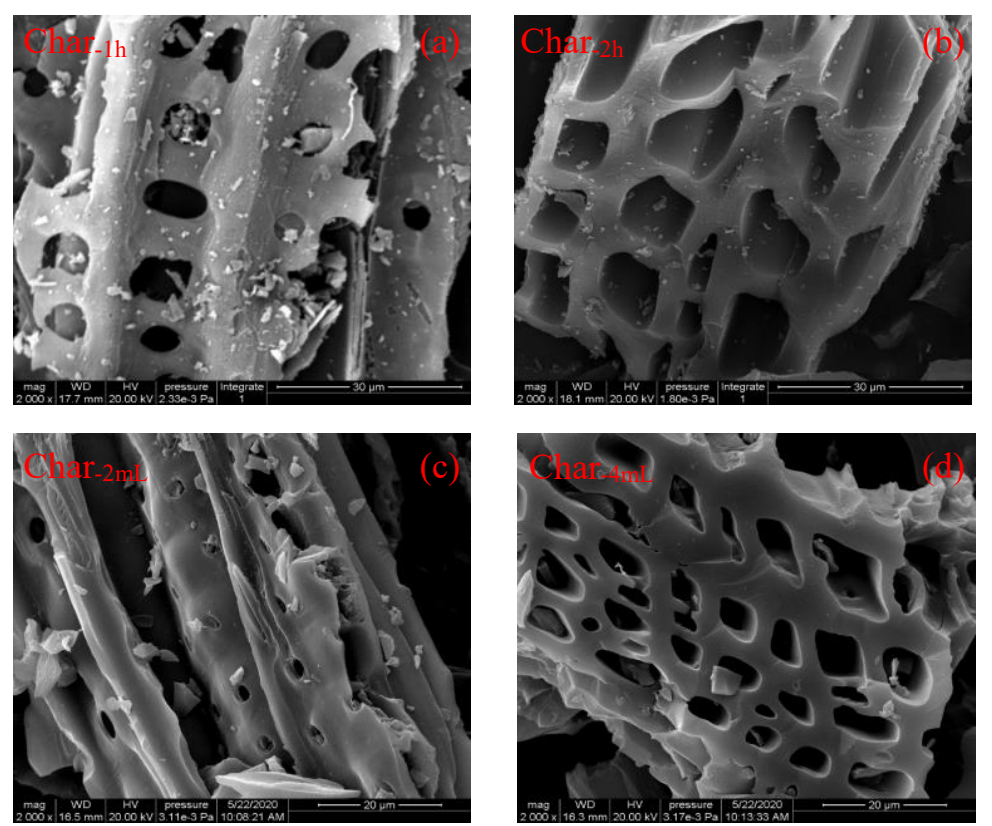

Figure 2. SEM images of AC 
surface pore structure of $\mathrm{AC}$ was abundant, and with the extension of activation reaction, not only the number of pores increased significantly, but also the surface structure presented a smooth trend. It indicated that $\mathrm{AC}$ had dense pore structure distribution, high pore volume and specific surface area, so theoretically, it had a large adsorption capacity for MB. This phenomenon agreed with the results of pore structure measurement.

\subsubsection{The analysis of chemical structure}

In order to determine the active sites in carbon structure for AC adsorption, Raman analysis was carried out in the wavelength range of $800-1800 \mathrm{~cm}^{-1}$. The peak fitting method was consistent with previous studies (Huang et al., 2020; Liu et al., 2021), and the analysis results were demonstrated in the Figure 3.
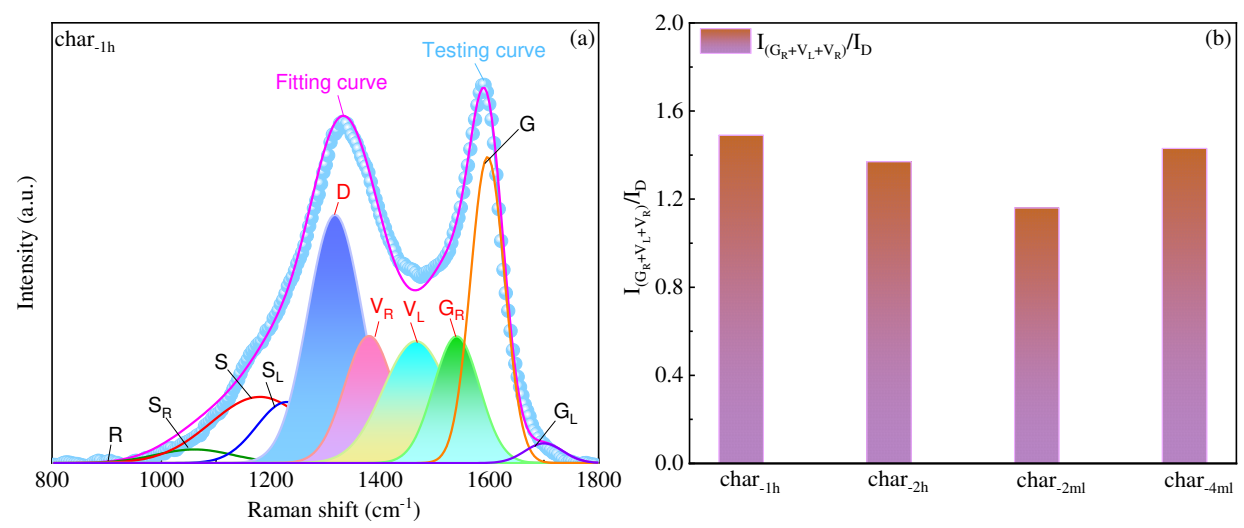

Figure 3. (a) A typical example of peak deconvolution for original Raman spectrum; (b) The Raman analysis of AC

It was clear that the change of $\mathrm{I}_{(\mathrm{GR}+\mathrm{VL}+\mathrm{VR})} / \mathrm{I}_{\mathrm{D}}$ was diverse with the extension of activation reaction. The $\mathrm{I}_{(\mathrm{GR}+\mathrm{VL}+\mathrm{VR})} / \mathrm{I}_{\mathrm{D}}$ value of $\mathrm{AC}$ prepared by $\mathrm{CO}_{2}$ activation showed a decreasing trend, mainly because the small aromatic ring system in the carbon 
structure was consumed during the activation process of biochar, which formed more defective structures and abundant pore structures. However, $\mathrm{H}_{2} \mathrm{O}$ activated biochar exhibited the opposite result. This may be due to the fact that the activation of $\mathrm{H}_{2} \mathrm{O}$ could penetrate into the interior of the carbon matrix, promoting the $\mathrm{H}, \mathrm{O}$, and $\mathrm{OH}$ free radicals disassociated by water vapor to change the surface morphology, similar conclusion was confirmed by Umemoto et al. (Umemoto et al., 2013). Therefore, it was not surprising that the $I_{D}$ value representing large aromatic ring in the surface carbon structure decreased. In addition, it had been confirmed that the mechanism of dye adsorption on biochar depended on the $\pi-\pi$ interaction between the graphite flakes of biochar and the aromatic ring structure of the dye (Qiu et al., 2009). In other words, the aromatic structure in $\mathrm{AC}$ was conductive to enhancing the adsorption of $\mathrm{MB}$.
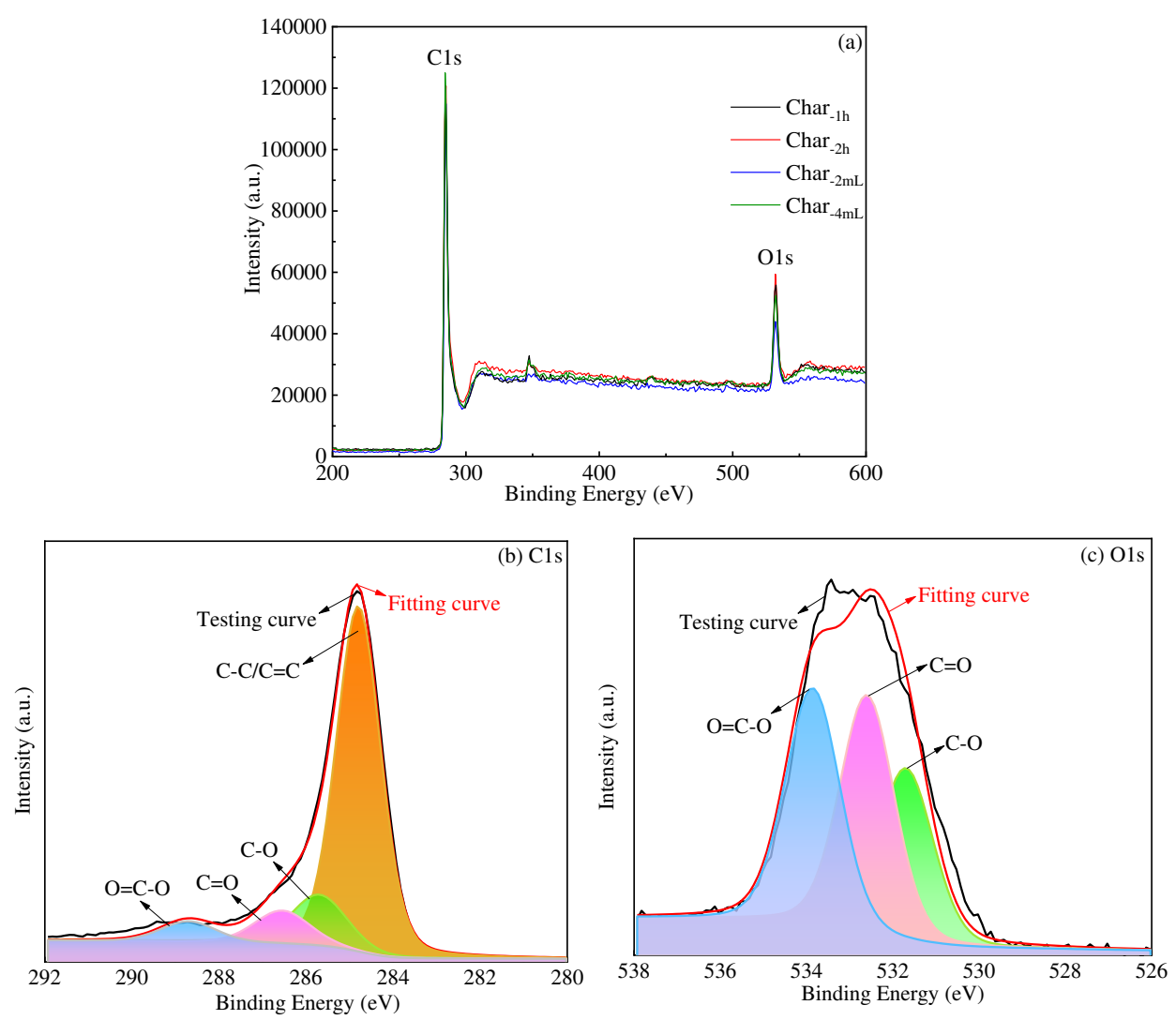

surface of AC.

Table 2. The XPS analysis results of AC

\begin{tabular}{ccccccccc}
\hline \multirow{2}{*}{ Sample } & $\mathrm{O} / \mathrm{C}$ & \multicolumn{4}{c}{$\mathrm{C} 1 \mathrm{~s}(\%)$} & \multicolumn{3}{c}{$\mathrm{O} 1 \mathrm{~s}(\%)$} \\
\cline { 3 - 9 } & & $\mathrm{C}-\mathrm{C} / \mathrm{C}=\mathrm{C}$ & $\mathrm{C}-\mathrm{O}$ & $\mathrm{C}=\mathrm{O}$ & $\mathrm{O}=\mathrm{C}-\mathrm{O}$ & $\mathrm{C}-\mathrm{O}$ & $\mathrm{C}=\mathrm{O}$ & $\mathrm{O}=\mathrm{C}-\mathrm{O}$ \\
\hline Char-1h & 0.08 & 68.32 & 14.35 & 5.61 & 11.72 & 31.81 & 37.18 & 31.01 \\
Char-2h & 0.09 & 66.67 & 21.57 & 2.46 & 9.30 & 40.16 & 33.25 & 26.59 \\
Char-2mL & 0.04 & 69.65 & 10.68 & 10.69 & 8.98 & 23.55 & 38.10 & 38.35 \\
Char-4mL & 0.04 & 66.77 & 18.26 & 6.80 & 8.17 & 26.23 & 34.48 & 39.29 \\
\hline
\end{tabular}

Figure 4. (a) The original XPS spectrum of AC; (b) The peak fitting of C1s; (c) The peak fitting of $\mathrm{O} 1 \mathrm{~s}$

XPS was used to analyzed the chemical combination forms of carbon and oxygen in AC. The total spectrum and the peak fitting of $\mathrm{C} 1 \mathrm{~s}$ and $\mathrm{O} 1 \mathrm{~s}$ were revealed in the Figure 4, while the combination form of $\mathrm{C}$ and $\mathrm{O}$ and the ratio of content were demonstrated in the Table 2. As for C1s peak fitting, it can be seen directly that when $\mathrm{CO}_{2}$ or $\mathrm{H}_{2} \mathrm{O}$ molecules contacted with biochar, the aromatic structure $(\mathrm{C}-\mathrm{C} / \mathrm{C}=\mathrm{C})$ in biochar decreased with the increase of reaction time. It was confirmed that gas phase in the activation process could better recombine with the char matrix, and the oxygen molecules in the gas phase acted as the active component of solid-gas phase interaction, which resulted in the formation of more oxygen-containing functional groups on the

Relevant studies (Luo \& Zhang, 2018; Meng et al., 2017) pointed out that the charbased materials contained abundant surface oxygen-containing functional groups, which could improve their activity performance by redistributing electronic structures, and the hydroxyl group was more powerful than that of carboxyl and carbonyl group. As the same time, it was also evident that the C-O group increased by about 3-8\% when 

found that the adsorption mechanism was significantly affected by the properties of surface functional groups, which played an important role in the adsorption of aromatic hydrocarbons on AC. It was worth mentioning that the $\mathrm{O} / \mathrm{C}$ value of $\mathrm{AC}$ activated by $\mathrm{CO}_{2}$ was significantly higher than that activated by $\mathrm{H}_{2} \mathrm{O}$. It was speculated that during the activation reaction, water vapor and carbon dioxide would dynamically change the carbon structure at multiple active sites of biochar, as well as the oxygen-containing functional groups, intermediates and free radicals formed by the reaction (Keown et al., 2008; Tay et al., 2013). As the reaction process progressed, the oxygen-containing functional groups in $\mathrm{AC}$ tended to increase, which revealed the presence of electronrich elements $(\mathrm{O})$ in the $\mathrm{AC}$ structure, resulting in the change of carbon surface structure. The change in the structure of biochar could lead to the enhancement of its adsorption capacity, which was confirmed by Shen et al. (Shen et al., 2014). It can't be ignored that the electrostatic attraction caused by the interaction between carboxyl and hydroxyl effect of different adsorption models. The isothermal adsorption curve of AC adsorbed 

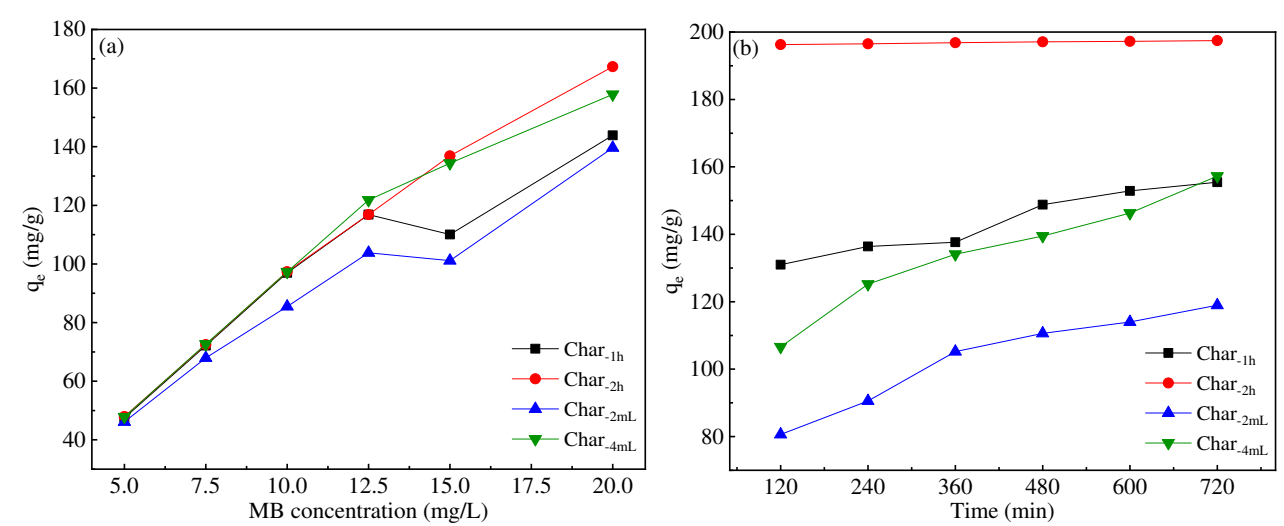

Figure 5. Effect of different experimental conditions on the adsorption of MB by AC. (a) Effect of initial concentration of $\mathrm{MB}(\mathrm{T}=298 \mathrm{~K}$, char dosage $=0.005 \mathrm{~g}$, contact time $=12 \mathrm{~h})$; (b) Effect of adsorption time $(\mathrm{T}=298 \mathrm{~K}$, char dosage $=0.005 \mathrm{~g}$, MB initial concentration $=20$ $\mathrm{mg} / \mathrm{L}$ )

As can be seen from the figure, with the increase of initial concentration, the adsorption isotherm tended to be flat and the adsorption rate gradually decreased. MB molecules occupied a large number of active sites, indicating that the adsorption capacity of $\mathrm{AC}$ would reach saturation. The maximum adsorption capacity of $\mathrm{AC}$ prepared under different activation states for MB was $140-160 \mathrm{mg} / \mathrm{g}$ when the initial concentration was $20 \mathrm{mg} / \mathrm{g}$, and $\mathrm{AC}$ prepared by $\mathrm{CO}_{2}$ activation for $2 \mathrm{~h}$ had the strongest adsorption capacity, which could also be confirmed by the above characterization results. Liu et al. (Liu \& Zhang, 2009) pointed out that the increase of the initial MB concentration improved the contract probability of biochar with MB and provided a driving force to overcome the transfer resistance between MB solution and biochar, resulting in an increase in the adsorption capacity of the biochar. As the active sites on 
the biochar became saturated at higher concentrations, the increase of adsorption capacity was limited. It was worth noting that the adsorption process of AC was assumed to be monolayer adsorption due to its relatively uniform surface, and there was no interaction in MB molecules, which was also proposed by Wu et al. (Wu et al., 2010).

Figure 5(b) showed that the adsorption rate was accelerated at the initial stage of adsorption (0-240 $\mathrm{min})$. On the one hand, due to the high concentration of $\mathrm{MB}$ in the solution, there was a large concentration gradient on the surface of the adsorbent, leading to a great adsorption power. On the other hand, there were abundant active sites on the surface of $\mathrm{AC}$ in the early stage of adsorption. With the extension of the adsorption time, the adsorption amount of $\mathrm{AC}$ to $\mathrm{MB}$ increased slowly and reached equilibrium at $12 \mathrm{~h}$. There was no doubt that $\mathrm{AC}$ activated by $\mathrm{CO}_{2}$ demonstrated a better adsorption performance.

\subsubsection{Adsorption kinetics}

The kinetic model was mainly applied to understand the interactions between adsorbent and adsorbate, which could more accurately distinguish the kinetic behavior at different stages, thus better explaining the adsorption mechanism of $\mathrm{AC}$ to $\mathrm{MB}$. The kinetic process of $\mathrm{AC}$ adsorption $\mathrm{MB}$ was fitted by pseudo-first-order and pseudosecond-order. The fitting effect and specific parameters were shown in the Figure 6 and

Table 3.

Table 3. Kinetic parameters obtained by various models for the adsorption of MB on AC

\begin{tabular}{cccccccc}
\hline \multirow{2}{*}{ Sample } & $\begin{array}{c}\mathrm{q}_{\mathrm{e}, \text { exp }} \\
(\mathrm{mg} / \mathrm{g})\end{array}$ & $\begin{array}{c}\mathrm{q}_{\mathrm{e}, 1} \\
(\mathrm{mg} / \mathrm{g})\end{array}$ & $\begin{array}{c}\mathrm{K}_{1} \\
\left(\mathrm{~min}^{-1}\right)\end{array}$ & $\mathrm{R}^{2}$ & $\begin{array}{c}\mathrm{q}_{\mathrm{e}, 2} \\
(\mathrm{mg} / \mathrm{g})\end{array}$ & $\begin{array}{c}\mathrm{K}_{2} \\
(\mathrm{~g} / \mathrm{mg} \cdot \mathrm{min})\end{array}$ & $\mathrm{R}^{2}$ \\
\hline Char $_{-1 \mathrm{~h}}$ & 155.46 & 56.51 & 0.0046 & 0.8746 & 163.40 & $1.35 \times 10^{-4}$ & 0.9967 \\
Char $_{-2 \mathrm{~h}}$ & 197.47 & 2.03 & 0.0034 & 0.9778 & 197.63 & $3.84 \times 10^{-3}$ & 0.9999 \\
\hline
\end{tabular}




\begin{tabular}{llllllll}
\hline Char-2mL & 118.95 & 70.84 & 0.0044 & 0.9891 & 132.98 & $7.96 \times 10^{-5}$ & 0.9964 \\
Char-4mL & 157.24 & 70.51 & 0.0030 & 0.9904 & 170.94 & $6.62 \times 10^{-5}$ & 0.9922 \\
\hline
\end{tabular}
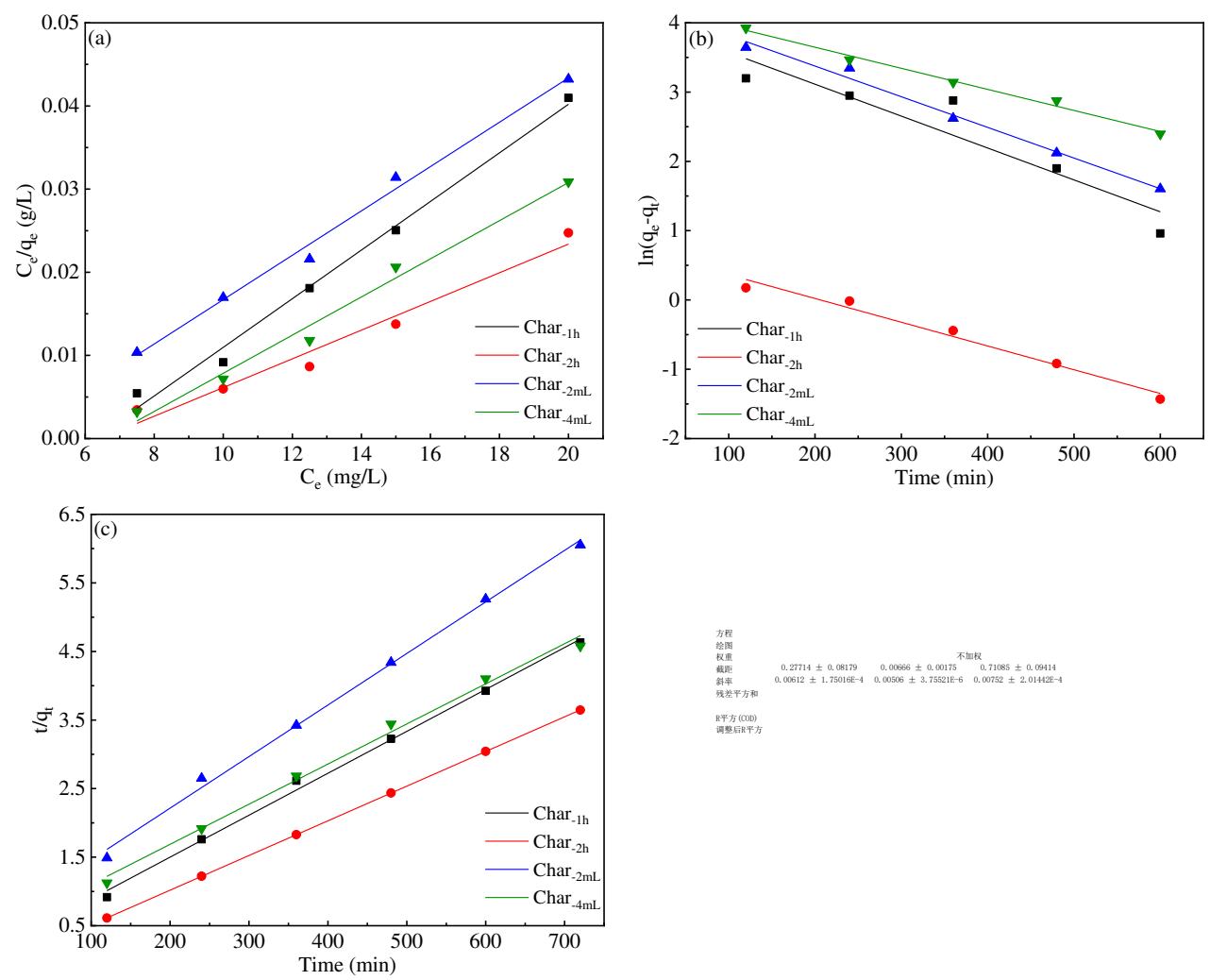

Figure 6. The kinetics of the adsorption system of $\mathrm{AC}$ to $\mathrm{MB}$

(a) Langmuir isotherms; (b) pseudo-first-order; (c) pseudo-second-order.

According to the fitting curve and the calculated relevant parameters, it was found that the fitting correlation coefficient $\mathrm{R}^{2}(0.9922-0.9999)$ of the pseudo-secondorder kinetic adsorption model was significantly better than that of the pseudo-firstorder (0.8746-0.9904), indicating that the pseudo-second-order kinetic equation could better describe the adsorption kinetic process of $\mathrm{AC}$ on $\mathrm{MB}$. In addition, the adsorption process was controlled by many dominant factors, which may include covalent bond formation, ion exchange-based chemical adsorption and pore-filling physical adsorption (Kang et al., 2018; Zhu et al., 2018). Since the pseudo-second-order kinetic 
model was based on chemical adsorption, adsorption of MB by AC was mainly classified into chemical adsorption, and the formation of chemical bond between AC surface and MB molecule was one of the important factors affecting the adsorption process (Bedin et al., 2016).

\subsection{Adsorption mechanism}

The adsorption mechanism was mainly reflected in the diffusion of adsorbent pores or particles, and the adsorption of adsorbate on the active sites of the adsorbent surface. Generally, adsorbents with large specific surface area can provide more active sites for adsorbates, which was conducive to the adsorption process (Bhatnagar et al., 2013). Some researchers (Fan et al., 2016; Leng et al., 2015) studied the similar adsorption mechanisms, and believed that the main mechanism of action included electrostatic interaction, ion exchange, surface complexation, physical adsorption, etc.. Surprisingly, oxygen-containing groups played an important role in the adsorption process.

Combined with the characterization of $\mathrm{AC}$ and the results of adsorption test on $\mathrm{MB}$, the adsorption mechanism of $\mathrm{MB}$ on $\mathrm{AC}$ was summarized in Figure 7. The high specific surface area and abundant pore structure of AC were important factors for efficient adsorption of MB. Simultaneously, the electrostatic interaction between the surface oxygen-containing functional groups in the adsorbents and the $\pi$ - $\pi$ interaction formed in the aromatic rings enhanced the adsorption capacity of AC to MB. 


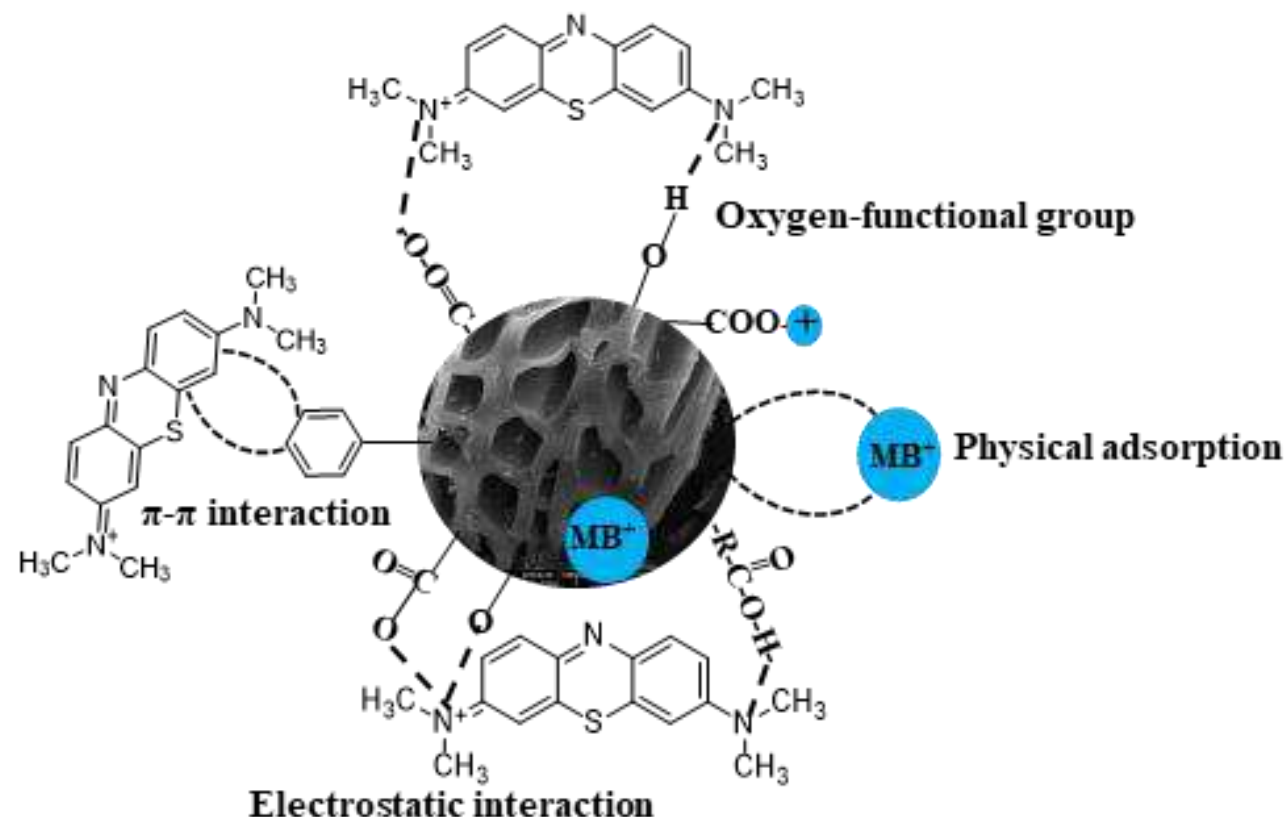

Figure 7. The possible adsorption mechanism of MB on AC.

\section{Conclusion}

In summary, a simple, low-cost and environmentally friendly activated biochar prepared by introducing the active agent, it not only obtained the large specific surface area and abundant oxygen-containing functional group, but also caused the $\pi-\pi$ interaction formed in the aromatic ring system of carbon structure and the electrostatic interaction generated by the groups. This made the activated biochar showed a great adsorption capacity to the methylene blue. In the adsorption experiment, the pseudosecond-order kinetic equation and Langmuir adsorption isotherm could better describe the adsorption process of methylene blue. It was worth mentioning that the main way of methylene blue adsorption on activated biochar was chemical adsorption, which was determined by the pore structure of activated biochar and the chemical properties of the interaction between activated biochar and methylene blue. Therefore, the prepared activated biochar was expected to be used as an excellent adsorbent for industrial 
pollutant treatment.

\section{Author contributions}

Shasha Liu: Conceptualization, Methodology, Writing - Original Draft. Chen Shen:

Data Curation. Yuhui Wang: Editing. Yong Huang: Supervision, Writing - Review \&

Editing, Project administration. Xun Hu: Visualization. Bin Li: Visualization. Karnowo:

Visualization. Jianbin Zhou: Supervision. Shu Zhang: Funding acquisition, Supervision,

Writing - Review \& Editing. Hong Zhang: Visualization.

\section{Availability of data and materials}

The datasets used and/or analyzed during the current study are available from the corresponding author on reasonable request.

\section{Funding}

This work was financially supported by the National Natural Science Foundation of

China (Grants 51876093 and 51876225); an internationally collaborative project

\section{Conflicts of interest}

339 There are no conflicts of interest to declare.

Ethics approval and consent to participate 
The author's statement of ethical clearance was conducted closely between parties involved in the research. All the authors have approved the manuscript and agreed with submission.

\section{Consent for publication}

All the authors have agreed with publication.

\section{References}

Bedin, K.C., Martins, A.C., Cazetta, A.L., Pezoti, O., Almeida, V.C. 2016. KOHactivated carbon prepared from sucrose spherical carbon: Adsorption equilibrium, kinetic and thermodynamic studies for Methylene Blue removal. Chemical Engineering Journal, 286, 476-484.

Bhatnagar, A., Hogland, W., Marques, M., Sillanpaa, M. 2013. An overview of the modification methods of activated carbon for its water treatment applications. Chemical Engineering Journal, 219, 499-511.

Choudhary, M., Kumar, R., Neogi, S. 2020. Activated biochar derived from Opuntia ficus-indica for the efficient adsorption of malachite green dye, $\mathrm{Cu}+2$ and $\mathrm{Ni}+2$ from water. Journal of Hazardous Materials, 392.

Deng, H., Li, A.Y., Ye, C.H., Sheng, L., Li, Z.P., Jiang, Y.H. 2020. Green Removal of Various Pollutants by Microsphere Adsorption: Material Characterization and Adsorption Behavior. Energy \& Fuels, 34(12), 16330-16340.

Fan, S.S., Tang, J., Wang, Y., Li, H., Zhang, H., Tang, J., Wang, Z., Li, X.D. 2016. Biochar prepared from co-pyrolysis of municipal sewage sludge and tea waste 
for the adsorption of methylene blue from aqueous solutions: Kinetics, isotherm, thermodynamic and mechanism. Journal of Molecular Liquids, 220, 432-441.

Fan, S.S., Wang, Y., Wang, Z., Tang, J., Tang, J., Li, X.D. 2017. Removal of methylene blue from aqueous solution by sewage sludge-derived biochar: Adsorption kinetics, equilibrium, thermodynamics and mechanism. Journal of Environmental Chemical Engineering, 5(1), 601-611.

Feng, D.D., Zhao, Y.J., Zhang, Y., Gao, J.M., Sun, S.Z. 2017a. Changes of biochar physiochemical structures during tar $\mathrm{H} 2 \mathrm{O}$ and $\mathrm{CO} 2$ heterogeneous reforming with biochar. Fuel Processing Technology, 165, 72-79.

Feng, D.D., Zhao, Y.J., Zhang, Y., Zhang, Z.B., Xu, H.H., Zhang, L.Y., Sun, S.Z. 2017b. Synergies and progressive effects of $\mathrm{H} 2 \mathrm{O} / \mathrm{CO} 2$ and nascent tar on biochar structure and reactivity during gasification. Fuel Processing Technology, 168, $1-10$.

Franciski, M.A., Peres, E.C., Godinho, M., Perondi, D., Foletto, E.L., Collazzo, G.C., Dotto, G.L. 2018. Development of CO2 activated biochar from solid wastes of a beer industry and its application for methylene blue adsorption. Waste Management, 78, 630-638.

Franz M, A.H.A., Pinto N G. . 2000. Effect of chemical surface heterogeneity on the adsorption mechanism of dissolved aromatics on activated carbon. Carbon, 38(13), 1807-1819.

Gao, Y., Yue, Q.Y., Gao, B.Y., Sun, Y.Y., Wang, W.Y., Li, Q., Wang, Y. 2013. Preparation of high surface area-activated carbon from lignin of papermaking black liquor 
by $\mathrm{KOH}$ activation for Ni(II) adsorption. Chemical Engineering Journal, 217, 345-353.

Genuino, D.A.D., de Luna, M.D.G., Capareda, S.C. 2018. Improving the surface properties of municipal solid waste-derived pyrolysis biochar by chemical and thermal activation: Optimization of process parameters and environmental application. Waste Management, 72, 255-264.

Huang, W., Chen, J., Zhang, J.Q. 2018. Adsorption characteristics of methylene blue by biochar prepared using sheep, rabbit and pig manure. Environmental Science and Pollution Research, 25(29), 29256-29266.

Huang, Y., Liu, S.S., Akhtar, M.A., Li, B., Zhou, J.B., Zhang, S., Zhang, H. 2020. Volatile-char interactions during biomass pyrolysis: Understanding the potential origin of char activity. Bioresource Technology, 316.

Kang, C.L., Zhu, L., Wang, Y.X., Wang, Y.H., Xiao, K.K., Tian, T. 2018. Adsorption of Basic Dyes Using Walnut Shell-based Biochar Produced by Hydrothermal Carbonization. Chemical Research in Chinese Universities, 34(4), 622-627.

Kang, W.M., Li, F., Zhao, Y.X., Qiao, C.M., Ju, J.G., Cheng, B.W. 2016. Fabrication of porous Fe2O3/PTFE nanofiber membranes and their application as a catalyst for dye degradation. Rsc Advances, 6(39), 32646-32652.

Keown, D.M., Hayashi, J.I., Li, C.Z. 2008. Drastic changes in biomass char structure and reactivity upon contact with steam. Fuel, 87(7), 1127-1132.

Leng, L.J., Yuan, X.Z., Huang, H.J., Shao, J.G., Wang, H., Chen, X.H., Zeng, G.M. 2015. Bio-char derived from sewage sludge by liquefaction: Characterization 
and application for dye adsorption. Applied Surface Science, 346, 223-231.

Li, T., Huang, P.W., Liao, T.W., Guo, J., Yu, X., Han, B.P., Peng, L., Zhu, Y., Zhang, Y.M. 2019a. Magnetic polymer-supported adsorbent with two functional adsorption sites for phosphate removal. Environmental Science and Pollution Research, 26(32), 33269-33280.

Li, Y.C., Xing, B., Wang, X.L., Wang, K.G., Zhu, L.J., Wang, S.R. 2019b. NitrogenDoped Hierarchical Porous Biochar Derived from Corn Stalks for PhenolEnhanced Adsorption. Energy \& Fuels, 33(12), 12459-12468.

Liu, S.S., Zhang, J., Wu, Y.S., Karnowo, Zhang, H., Li, B., Hu, X., Sun, H.Q., Zhou, J.B., Huang, Y., Zhang, S. 2021. The effect of carbon structure in chars on Fe migration and its catalytic activity for benzyl phenyl ether decomposition. Journal of Analytical and Applied Pyrolysis, 154.

Liu, Z.G., Zhang, F.S. 2009. Removal of lead from water using biochars prepared from hydrothermal liquefaction of biomass. Journal of Hazardous Materials, 167(13), 933-939.

Luo, D., Zhang, X.Q. 2018. The effect of oxygen containing functional groups on the H-2 adsorption of graphene based nanomaterials: experiment and theory. International Journal of Hydrogen Energy, 43(11), 5668-5679.

Lyu, H.H., Gao, B., He, F., Zimmerman, A.R., Ding, C., Tang, J.C., Crittenden, J.C. 2018. Experimental and modeling investigations of ball-milled biochar for the removal of aqueous methylene blue. Chemical Engineering Journal, 335, 110119. 
Meng, X.L., Gao, M.Q., Chu, R.Z., Miao, Z.Y., Wu, G.G., Bai, L., Liu, P., Yan, Y.F., Zhang, P.C. 2017. Construction of a macromolecular structural model of Chinese lignite and analysis of its low-temperature oxidation behavior. Chinese Journal of Chemical Engineering, 25(9), 1314-1321.

Pirsaheb, M., Rezai, Z., Mansouri, A.M., Rastegar, A., Alahabadi, A., Sani, A.R., Sharafi, K. 2016. Preparation of the activated carbon from India shrub wood and their application for methylene blue removal: modeling and optimization. Desalination and Water Treatment, 57(13), 5888-5902.

Qiu, Y.P., Zheng, Z.Z., Zhou, Z.L., Sheng, G.D. 2009. Effectiveness and mechanisms of dye adsorption on a straw-based biochar. Bioresource Technology, 100(21), $5348-5351$.

Rajapaksha, A.U., Chen, S.S., Tsang, D.C.W., Zhang, M., Vithanage, M., Mandal, S., Gao, B., Bolan, N.S., Ok, Y.S. 2016. Engineered/designer biochar for contaminant removal/immobilization from soil and water: Potential and implication of biochar modification. Chemosphere, 148, 276-291.

Rajapaksha, A.U., Vithanage, M., Ahmad, M., Seo, D.C., Cho, J.S., Lee, S.E., Lee, S.S., Ok, Y.S. 2015. Enhanced sulfamethazine removal by steam-activated invasive plant-derived biochar. Journal of Hazardous Materials, 290, 43-50.

Shen, Y.F., Zhao, P.T., Shao, Q.F., Ma, D.C., Takahashi, F., Yoshikawa, K. 2014. In-situ catalytic conversion of tar using rice husk char-supported nickel-iron catalysts for biomass pyrolysis/gasification. Applied Catalysis B-Environmental, 152, $140-151$. 
Shirani, Z., Song, H., Bhatnagar, A. 2020. Efficient removal of diclofenac and cephalexin from aqueous solution using Anthriscus sylvestris-derived activated biochar. Science of the Total Environment, 745.

Tay, H.L., Kajitani, S., Zhang, S., Li, C.Z. 2013. Effects of gasifying agent on the evolution of char structure during the gasification of Victorian brown coal. Fuel, $103,22-28$.

Tran, H.N., You, S.J., Chao, H.P. 2017. Fast and efficient adsorption of methylene green 5 on activated carbon prepared from new chemical activation method. Journal of Environmental Management, 188, 322-336.

Umemoto, S., Kajitani, S., Hara, S. 2013. Modeling of coal char gasification in coexistence of $\mathrm{CO} 2$ and $\mathrm{H} 2 \mathrm{O}$ considering sharing of active sites. Fuel, 103, 1421.

Wan, X.Y., Zhan, Y.Q., Long, Z.H., Zeng, G.Y., He, Y. 2017. Core@double-shell structured magnetic halloysite nanotube nano-hybrid as efficient recyclable adsorbent for methylene blue removal. Chemical Engineering Journal, 330, 491-504.

Wu, F.C., Liu, B.L., Wu, K.T., Tseng, R.L. 2010. A new linear form analysis of RedlichPeterson isotherm equation for the adsorptions of dyes. Chemical Engineering Journal, 162(1), 21-27.

Xu, D.L., Gao, Y.X., Lin, Z.X., Gao, W.R., Zhang, H., Karnowo, K., Hu, X., Sun, H.Q., Syed-Hassan, S.S.A., Zhang, S. 2020. Application of Biochar Derived From Pyrolysis of Waste Fiberboard on Tetracycline Adsorption in Aqueous Solution. 
Yang, Z.J., Hou, J., Miao, L.Z., Wu, J. 2021. Comparison of adsorption behavior studies of methylene blue by microalga residue and its biochars produced at different pyrolytic temperatures. Environmental Science and Pollution Research, 28(11), 14028-14040.

Yu, M., Li, J., Wang, L.J. 2016. Preparation and characterization of magnetic carbon aerogel from pyrolysis of sodium carboxymethyl cellulose aerogel crosslinked by iron trichloride. Journal of Porous Materials, 23(4), 997-1003.

Zeng, Z.W., Tan, X.F., Liu, Y.G., Tian, S.R., Zeng, G.M., Jiang, L.H., Liu, S.B., Li, J., Liu, N., Yin, Z.H. 2018. Comprehensive Adsorption Studies of Doxycycline and Ciprofloxacin Antibiotics by Biochars Prepared at Different Temperatures. Frontiers in Chemistry, 6.

Zhu, Y., Yi, B.J., Yuan, Q.X., Wu, Y.L., Wang, M., Yan, S.P. 2018. Removal of methylene blue from aqueous solution by cattle manure-derived low temperature biochar. Rsc Advances, 8(36), 19917-19929. 
Figures
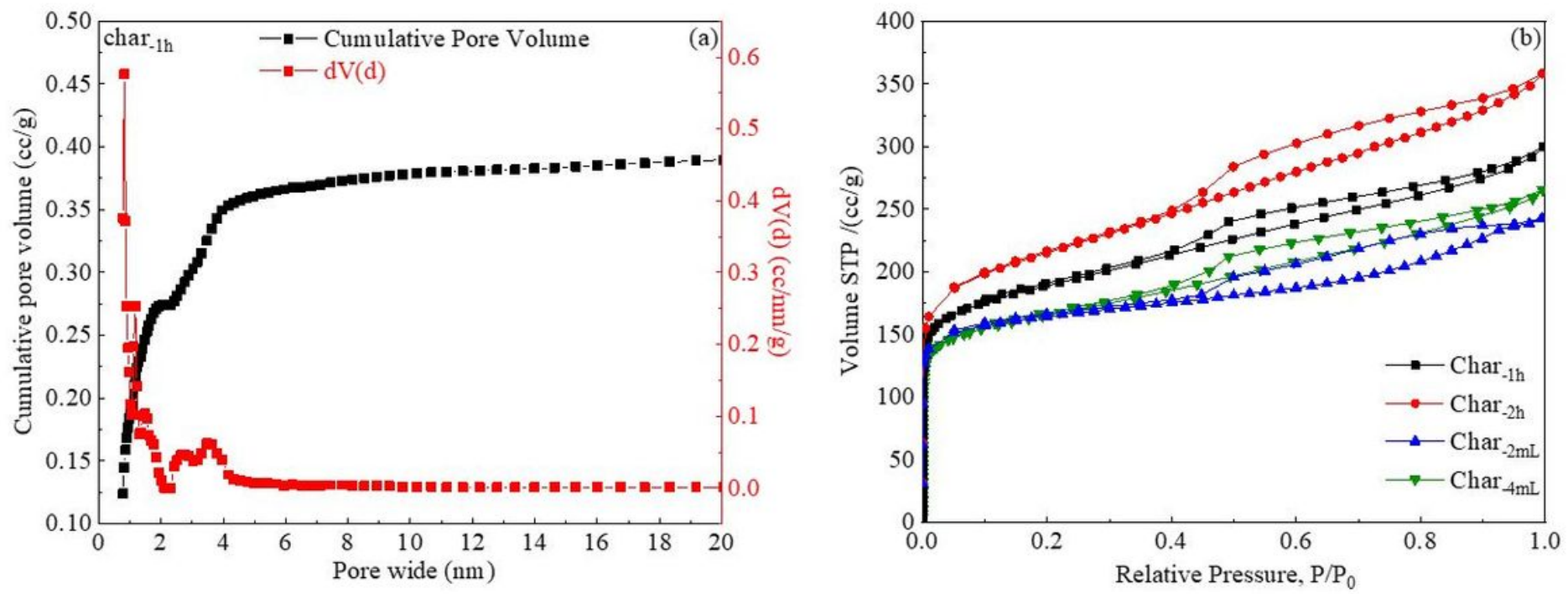

Figure 1

(a) Diagram of pore distribution; (b) N2 adsorption/desorption isotherms of AC. 

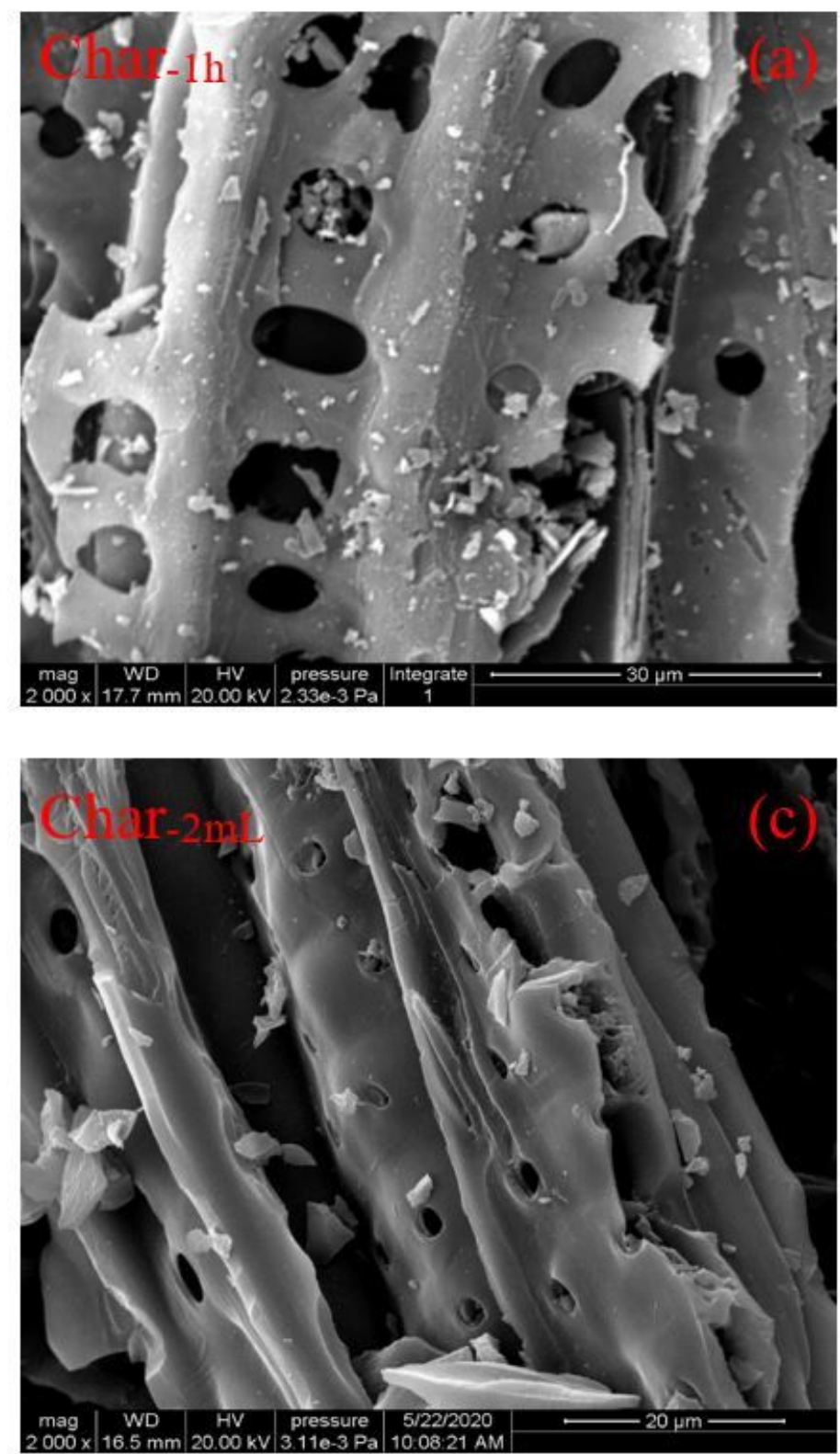
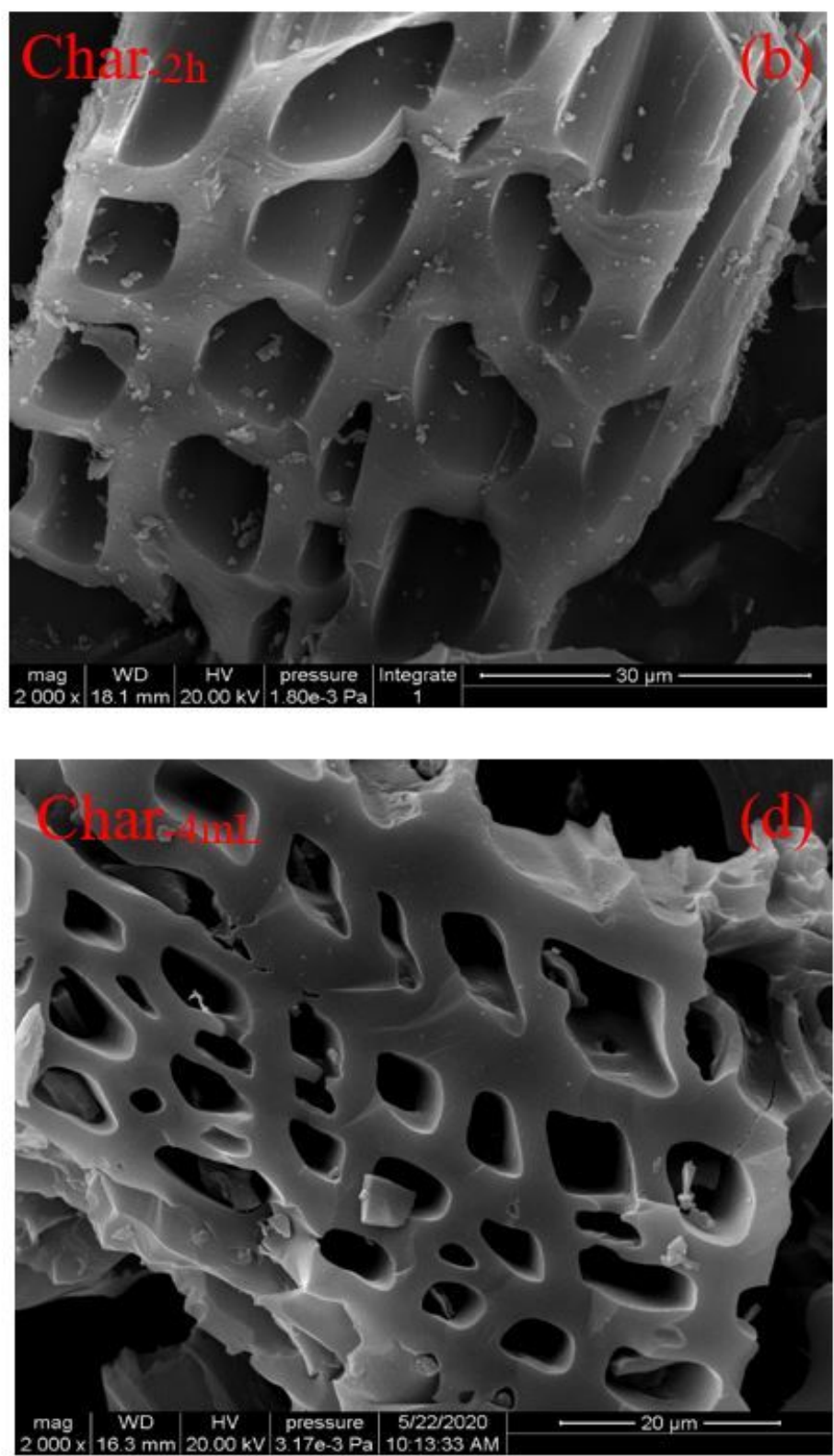

Figure 2

SEM images of AC 

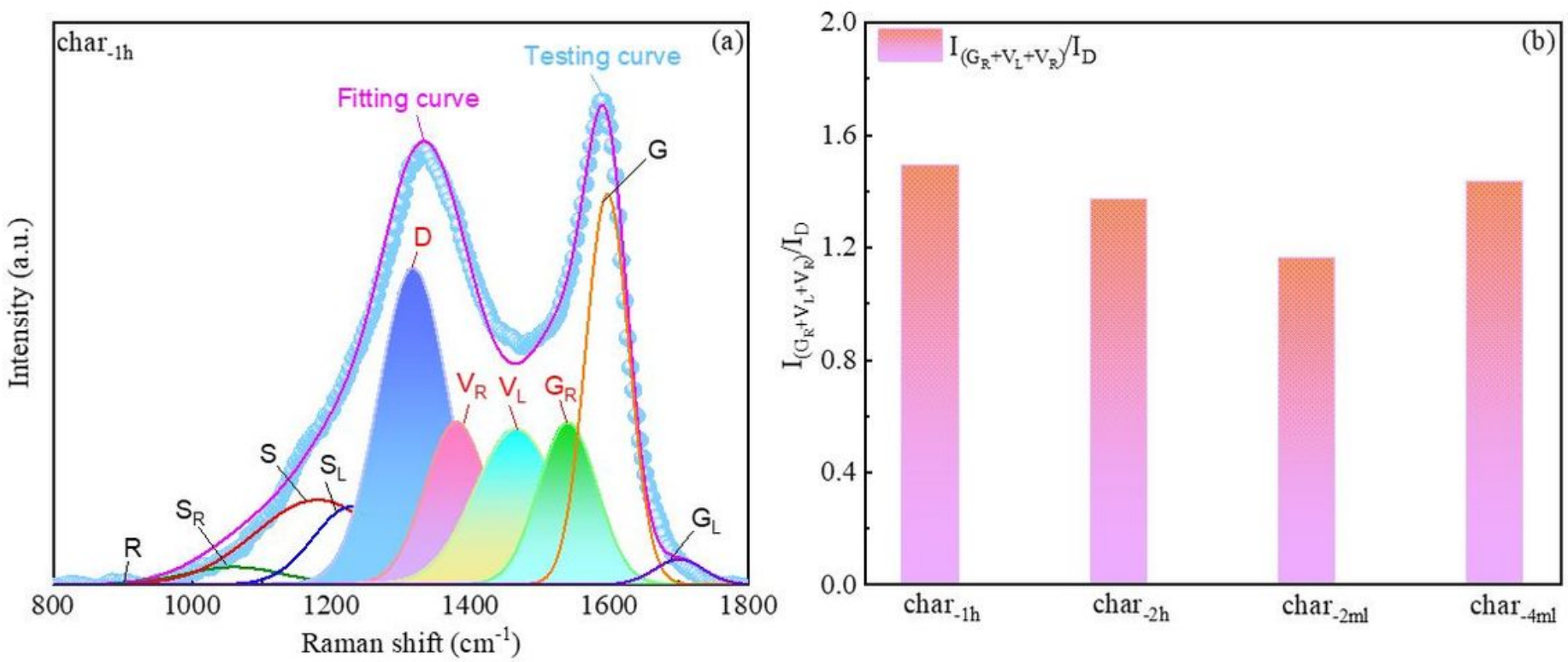

Figure 3

(a) A typical example of peak deconvolution for original Raman spectrum; (b) The Raman analysis of AC 

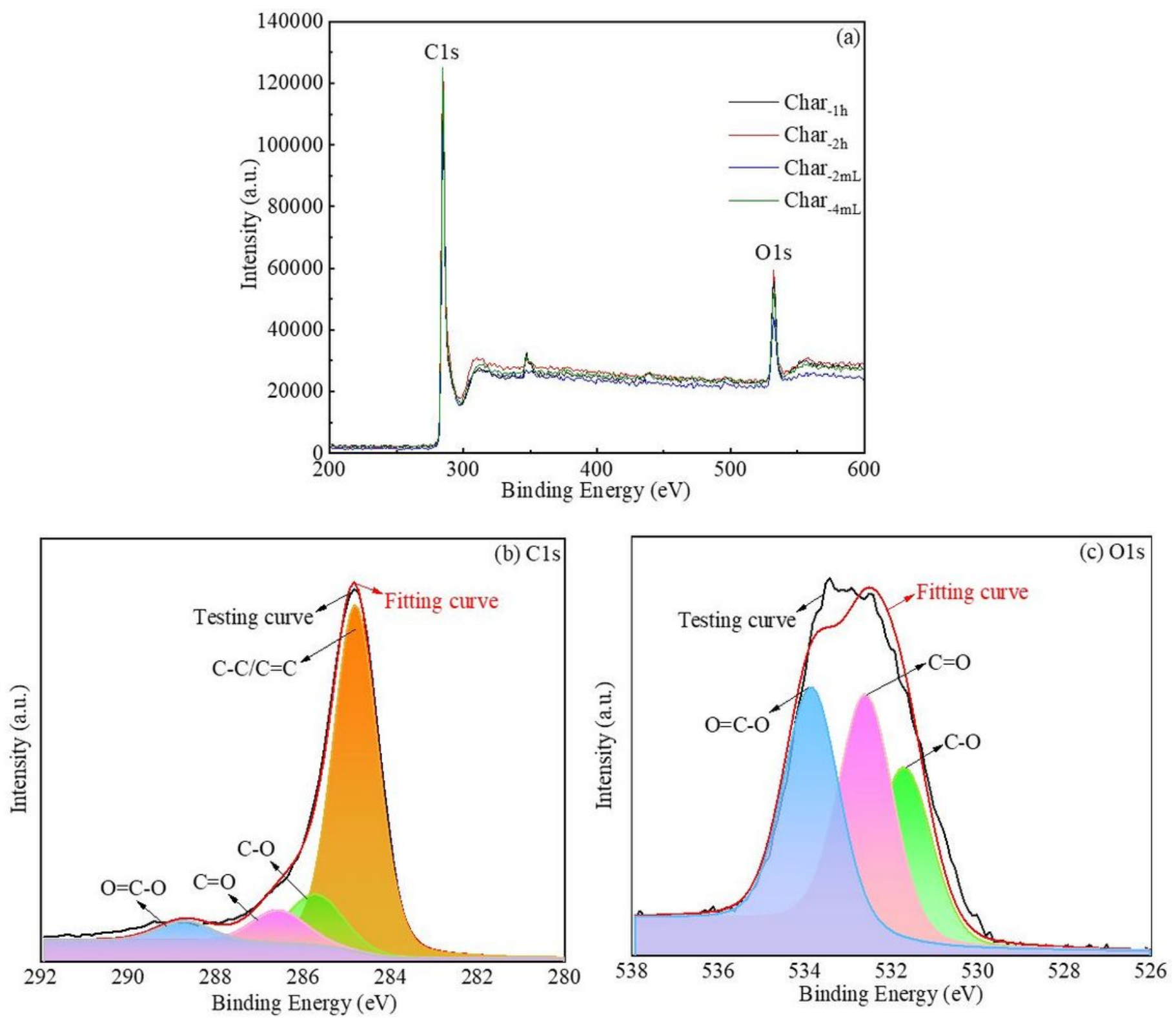

Figure 4

(a) The original XPS spectrum of AC; (b) The peak fitting of C1s; (c) The peak fitting of 01s 

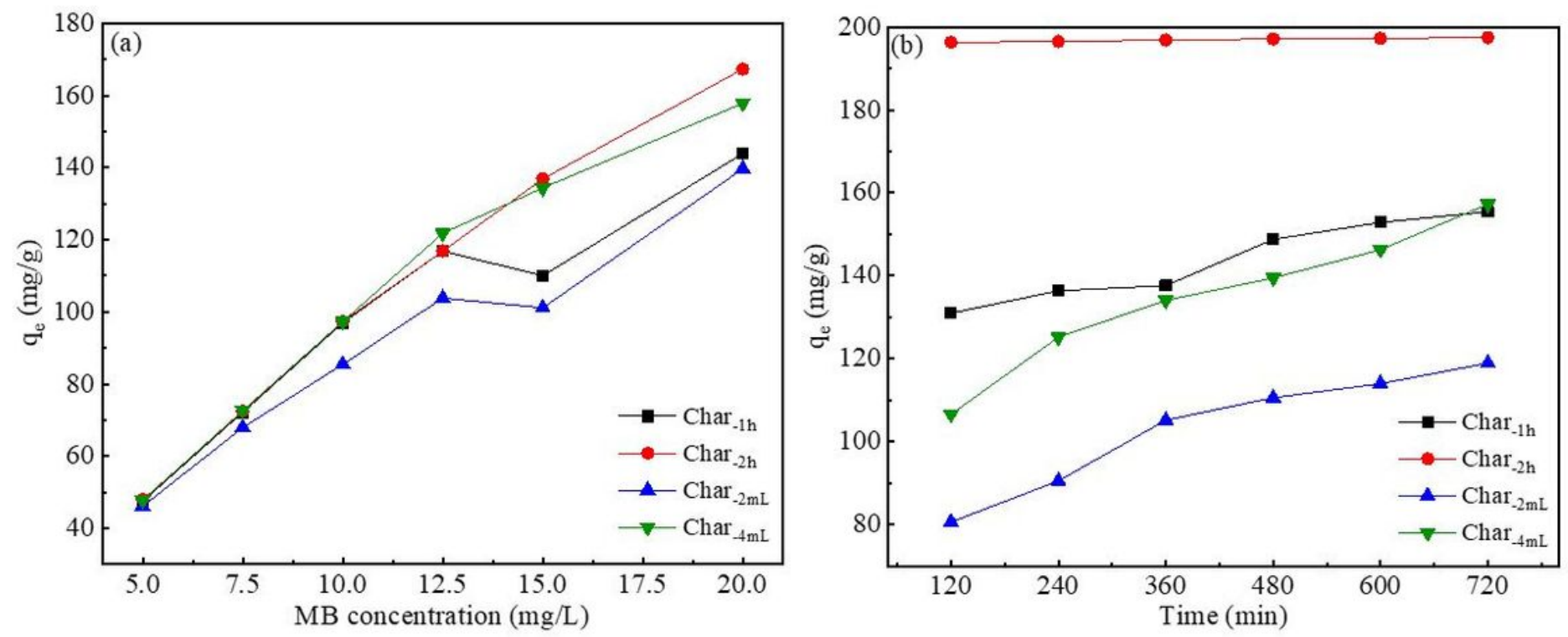

Figure 5

Effect of different experimental conditions on the adsorption of MB by AC. (a) Effect of initial concentration of $M B(T=298 \mathrm{~K}$, char dosage $=0.005 \mathrm{~g}$, contact time $=12 \mathrm{~h})$; (b) Effect of adsorption time ( $\mathrm{T}=298 \mathrm{~K}$, char dosage $=0.005 \mathrm{~g}, \mathrm{MB}$ initial concentration $=20 \mathrm{mg} / \mathrm{L}$ ) 

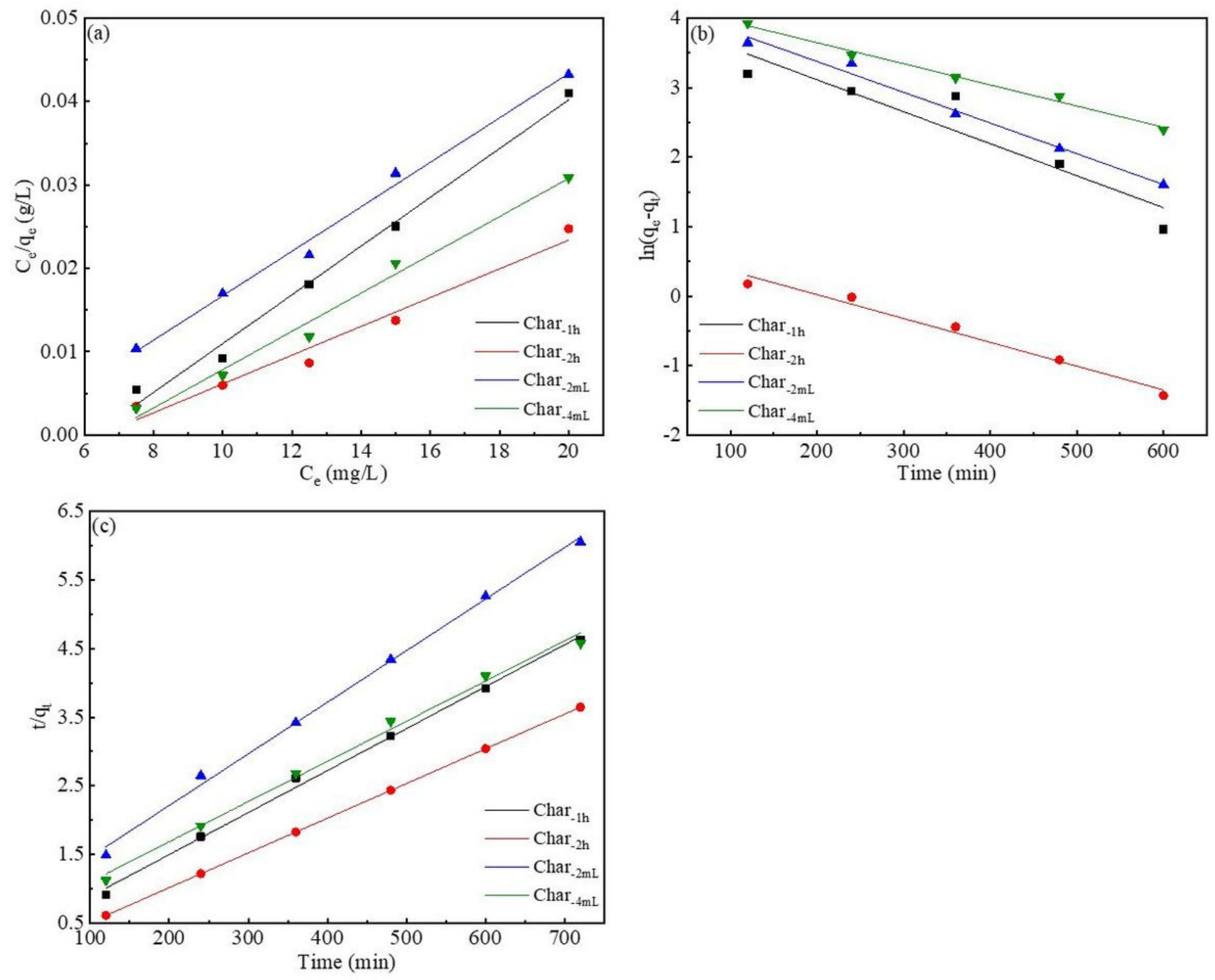

\section{Figure 6}

The kinetics of the adsorption system of AC to MB (a) Langmuir isotherms; (b) pseudo-first-order; (c) pseudo-second-order. 


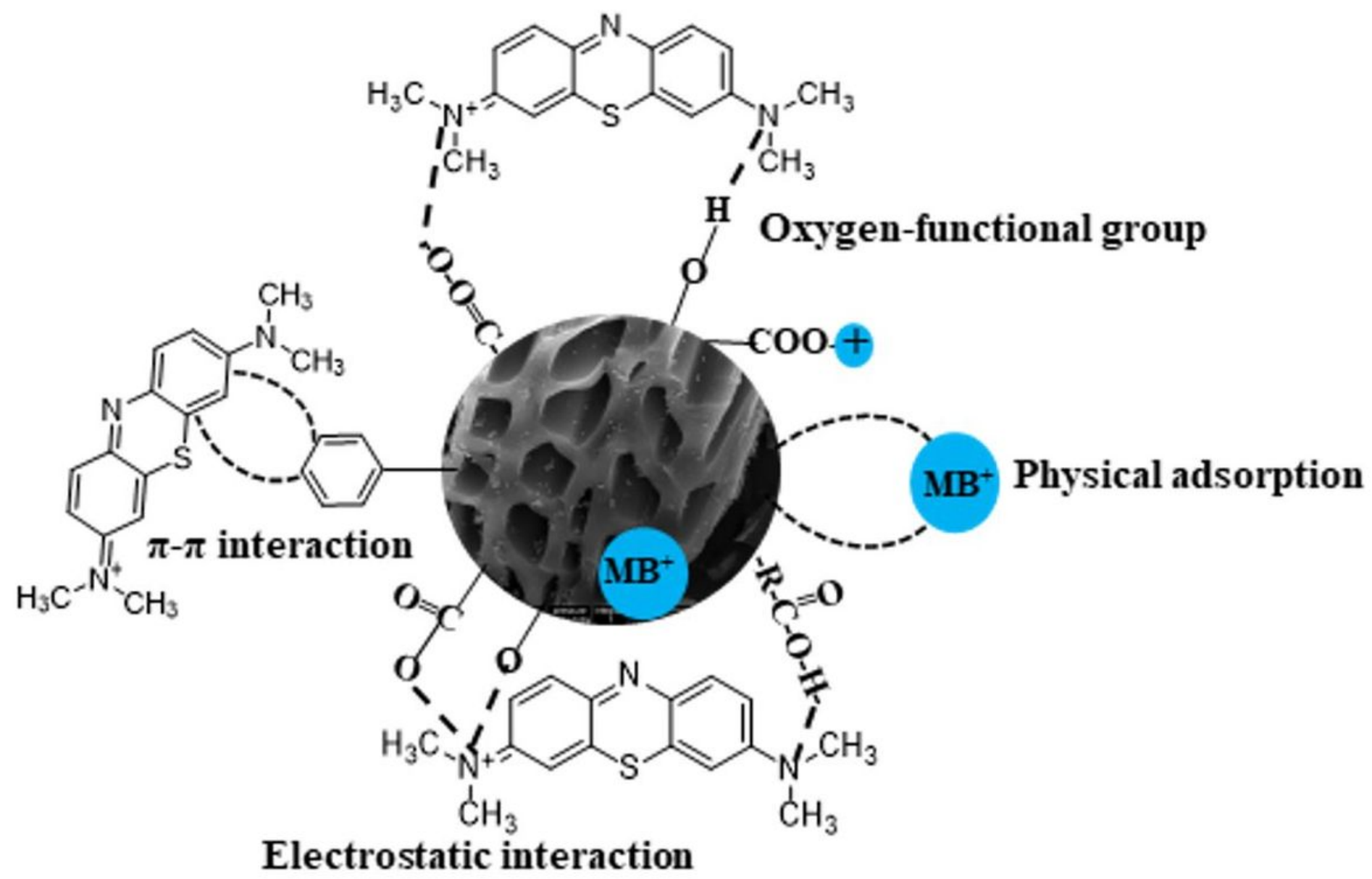

Figure 7

The possible adsorption mechanism of MB on AC. 